Check for updates

Cite this: Chem. Sci., 2019, 10, 7246

๑ All publication charges for this article have been paid for by the Royal Society of Chemistry

Received 16th May 2019

Accepted 12th June 2019

DOI: $10.1039 / c 9 s c 02380 a$

rsc.li/chemical-science

\title{
Palladium-catalyzed enantioselective alkenylation of alkenylbenzene derivatives $\uparrow$
}

\author{
Zhi-Min Chen, (D) \$\& Jianbo Liu, $\$$ Jing-Yao Guo, Maximillan Loch, (D) Ryan J. DeLuca \\ and Matthew S. Sigman (D) *
}

A regioselective and enantioselective palladium-catalyzed relay Heck alkenylation of alkenylbenzene derivatives to construct remote stereocenters is disclosed. Various $\beta$-substituted styrenes were readily obtained in moderate yields with good to excellent levels of enantioselectivity. This strategy provides rapid access to enantioenriched $\delta, \varepsilon, \zeta$, and $\eta$-alkenyl aryl compounds from simple starting materials. Mechanistic studies suggest that termination of the relay reaction is controlled by affinity of the arene for the Pd complex during migration.

\section{Introduction}

The migration of a metal through an alkyl chain via iterative $\beta$ hydride elimination/migratory insertion processes, often termed chain walking (or running) offers the opportunity to effectively functionalize multiple sites on a substrate. ${ }^{1}$ Initiation of this process is often accomplished through a metal-catalysed migratory insertion event of an alkene with applications in areas ranging from olefin polymerization ${ }^{2}$ to asymmetric catalysis. ${ }^{3}$ After the initial migratory insertion and subsequent chain walking, termination events are often coupled with either a functionalization of a metal-alkyl intermediate or reestablishing the unsaturation. ${ }^{4}$

In this context, our lab has developed various enantioselective Heck-type reactions of di- and tri-substituted alkenes wherein the reaction is terminated by formation of a carbonyl derivative (Scheme 1A). ${ }^{3,5}$ The formation of the aldehyde facilitates this in two key regards: (1) the penultimate proposed intermediate (C) is thermodynamically stabilized according to computational studies and (2) the resulting aldehyde does not participate in migratory insertion events thus making the process irreversible. ${ }^{6}$ Coupled together, expanding the scope of chain walking events within a Heck platform will likely require similar tactics.

In this regard, our lab disclosed an enantioselective relay Heck arylation of alkenyl carbonyl derivatives, which delivered $\alpha, \beta$ unsaturated compounds containing remote stereocenters (Scheme 1B).7 The $\alpha, \beta$-unsaturated carbonyls are poor ligands

Department of Chemistry, University of Utah, 315 South 1400 East, Salt Lake City, Utah 84112, USA. E-mail: sigman@chem.utah.edu

$\uparrow$ Electronic supplementary information (ESI) available. See DOI: 10.1039/c9sc02380a

\$ Z.-M. C. and J. L. contributed equally to this work.

$\S$ Present address: Shanghai Key Laboratory for Molecular Engineering of Chiral Drugs, School of Chemistry and Chemical Engineering, Shanghai Jiao Tong University, 800 Dongchuan Road, Shanghai 200240, P. R. China. compared to the initial electron rich alkene and do not participate in further Heck reactions. Combined, these results provide a basis for exploring other termination possibilities to expand the scope of these enantioselective processes. As an example, we

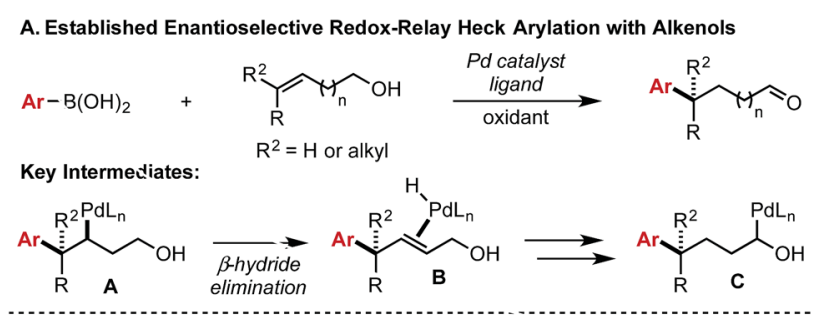

B. Established Enantioselective Relay Heck Arylation with Carboriyl Derivatives

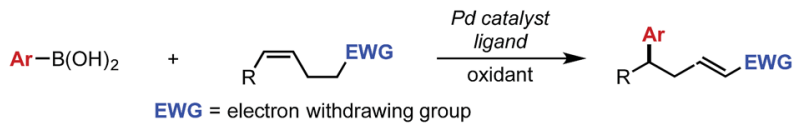

C. Proposed Alkenylation of Alkenylbenzene Derivatives

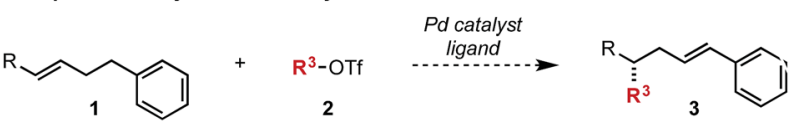

Mechanistic Considerations:
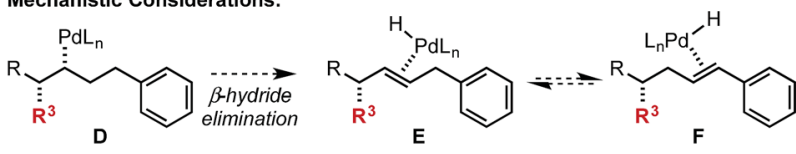
migratory
insertion

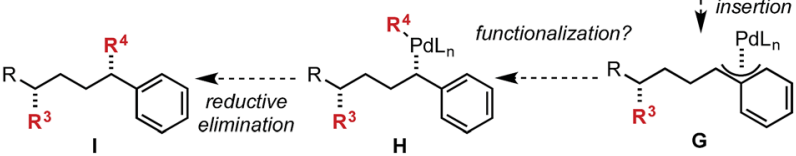

-Will Pd migrate toward the aryl group? • Selective $\beta$-hydride elimination? - Reinsertion of alkene $\mathrm{F}$ into the $\mathrm{Pd}-\mathrm{H}$ bond to form a $\pi$-benzyl complex ?

- Can a difunctionalization be achieved?

Scheme 1 Previous work with carbonyl derivatives and proposed work with alkenylbenzene derivatives. 
initially envisaged an aryl group could be employed to deliver a styrenyl product (3) or, with the addition of a transmetallating reagent, a remotely difunctionalized product (I) (Scheme 1C). From a mechanistic perspective, the Pd-alkyl intermediate (D) arising from alkene $\mathbf{1}$ and alkenyl triflate 2 could undergo $\beta$ hydride elimination away from the newly formed stereocenter to deliver intermediate $\mathbf{E}$. We postulated that alkene $\mathbf{E}$ would be in equilibrium with alkene $\mathbf{F}$, which would ultimately provide the thermodynamically more stable styrene product (3) after dissociation of the Pd-hydride. However, styrene $\mathbf{F}$ could reinsert into the Pd-hydride bond to produce the stabilized $\pi$-benzyl intermediate (G) that could be intercepted with a transmetallating reagent to afford intermediate $\mathbf{H}$ followed by reductive elimination to deliver product I (in which two new stereocenters were formed). Herein, we demonstrate that the styrene product is favoured and can be produced in high enantioselectivity. Of perhaps more interest, we provide mechanistic evidence to why the reaction terminates in this fashion.

\section{Results and discussion}

To initiate our investigation, $\operatorname{Pd}_{2}(\mathrm{dba})_{3}$ and a pyridine oxazoline (PyrOx) ligand were combined with alkenylbenzene 1a and alkenyl triflate 2a under previously reported relay Heck conditions for substrates of this type (Table 1$).{ }^{8}$ Under these conditions, styrenyl product 3a was isolated in $42 \%$ yield and $96: 4$ er (entry 1). The mass balance was a mixture of the undesired migratory insertion product (insertion at the alkene carbon proximal to the aryl group) and other alkene isomers 4 . Switching the precatalyst to $\operatorname{Pd}(\mathrm{dba})_{2}$ led to a slight increase in yield (entry 2) which was further improved to $55 \%$ with the addition of $7.5 \mathrm{~mol} \%$ dba (entry 3$).{ }^{9}$ Additionally, during the course of our optimization, the effect of phenylboronic acid addition was evaluated (to explore the possibility of a remote

Table 1 Reaction optimization ${ }^{a}$

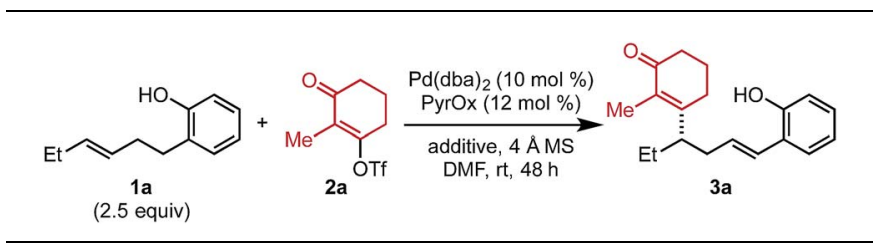

\begin{tabular}{|c|c|c|c|}
\hline Entry & Additive (mol\%) & $\begin{array}{l}\% \\
\text { Yield }\end{array}$ & $\mathrm{Er}$ \\
\hline $1^{b}$ & - & 42 & $96: 4$ \\
\hline 2 & - & 48 & $95.5: 4.5$ \\
\hline 3 & $\mathrm{dba}(7.5)$ & 55 & $95.5: 4.5$ \\
\hline 4 & $\mathrm{dba}(7.5)+5 \mathrm{a}(110)$ & 60 & $95.5: 4.5$ \\
\hline 5 & $\mathrm{dba}(7.5)+5 \mathrm{~b}(110)$ & 69 & $95.5: 4.5$ \\
\hline
\end{tabular}

${ }^{a}$ Each entry represents the isolated yield on $0.2 \mathrm{mmol}$ scale. Er values were determined by SFC. ${ }^{b} \operatorname{Pd}_{2}(\mathrm{dba})_{3}(5 \mathrm{~mol} \%)$ was used. difunctionalization reaction), which resulted in an increase in the isolated yield of styrenyl product 3a (entry 4). Lastly, the addition of electron-rich para-methoxyphenylboronic acid improved the yield to $69 \%$ (entry 5). It should be noted that no remote difunctionalization product was observed with either arylboronic acid additive (entries 4 and 5); however, the yield of the styrenyl product is increased.

After optimized conditions were identified (entry 5), the scope of the alkenylbenzene substrate was explored (Table 2). In general, the desired styrenyl products were obtained with moderate yields and excellent enantiomeric ratios. Again, alkenyl triflate 2a was completely converted and the mass balance was mainly composed of alkene isomers 4 (a putative explanation is discussed below). A phenyl group on the substrate (1b) gave the desired styrenyl product in $64 \%$ and 96.5 : 3.5 er. A variety of electron-rich aryl groups were welltolerated including $p$-methyl (3c), $p$-methoxy (3d), o-methoxy (3e), $p$-hydoxy (3f), and $p$-dimethylamino (3g).

Additionally, electron-withdrawing substituents such as an ethyl ester (3h), two methoxy groups at the meta positions (3i), and a trifluoromethyl group (3j) were all competent. A fluorine atom was readily incorporated on the aromatic ring (3k-3m). Substrates containing naphthyl groups (1n and 1o) produced the desired products $3 \mathbf{n}$ and $3 \mathbf{o}$ in $57 \%$ and $44 \%$ yield, respectively. A benzodioxole group (1p) was successfully incorporated delivering styrenyl product $3 p$ in $42 \%$ yield and $95: 5$ er. Lastly, a fluoropyridyl group (1q) delivered the corresponding product (3q) in $66 \%$ yield. Trisubstituted alkene substrates were also evaluated under the reaction conditions but no desired product was observed. It should be noted that the absolute configuration of $3 \mathbf{d}$ was determined to be $(S)$ and thus the rest of the products were assigned as $(S)$ by analogy. ${ }^{10}$

Next, the scope of alkenyl triflates was investigated (Table 3). For example, 5,5-dimethylcyclohexenone triflate (2r) and 2bromo-substituted triflate $2 \mathrm{~s}$ gave the corresponding products ( $3 \mathbf{r}$ and $3 \mathbf{s}$ ) in $41 \%$ and $30 \%$ yield, respectively. An enol triflate containing a methyl-substituted cyclopentenone (2t) delivered product 3t in $45 \%$ yield and $97.5: 2.5$ er. Reaction with $\beta$-keto ester derived triflates $\mathbf{1} \mathbf{u}$ and $\mathbf{1} \mathbf{v}$ yielded the desired products $(3 \mathbf{u}$, $3 \mathrm{v})$ in $52 \%$ and $60 \%$ yield, respectively. A $\beta$-keto ester derived triflate containing a Boc-protected amine $(1 \mathbf{w})$ produced $3 \mathbf{w}$ in $61 \%$ yield and $98: 2$ er. Additionally, an enol triflate containing a phthalimide (1x) furnished the desired styrenyl product in $51 \%$ yield and $99: 1$ er. The isolated yields of products $3 \mathbf{u}, 3 \mathbf{v}$, and $\mathbf{3 w}$ were determined after hydrogenation, as a mixture of alkene isomers were produced and complicated purification.

The effect of chain length on yield and selectivity was determined by comparing three additional substrates containing additional methylene units between the alkene and the aryl moiety (1y-1aa) (Table 4). When bishomoallylic aryl compound $1 \mathbf{y}$ was subjected to the standard reaction conditions followed by hydrogenation, product $3 y$ was obtained in $63 \%$ (2.6 : 1.0 ratio of insertion products). Trishomoallylic aryl compound $\mathbf{1 z}$ delivered product $\mathbf{3 z}$ in similar yield and insertion selectivity, albeit with a slightly diminished er. Lastly, when the substrate contained an additional methylene unit (1aa), product 3aa was observed in $57 \%$ yield and reduced site selectivity $(2.0: 1.0$ mixture of 
Table 2 Evaluation of alkenylbenzene substrates ${ }^{a}$
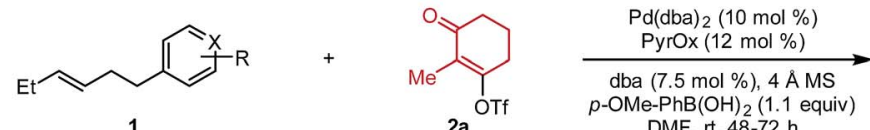

(2.5 equiv)

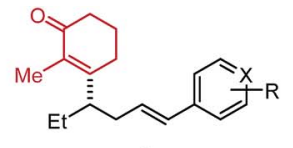

3
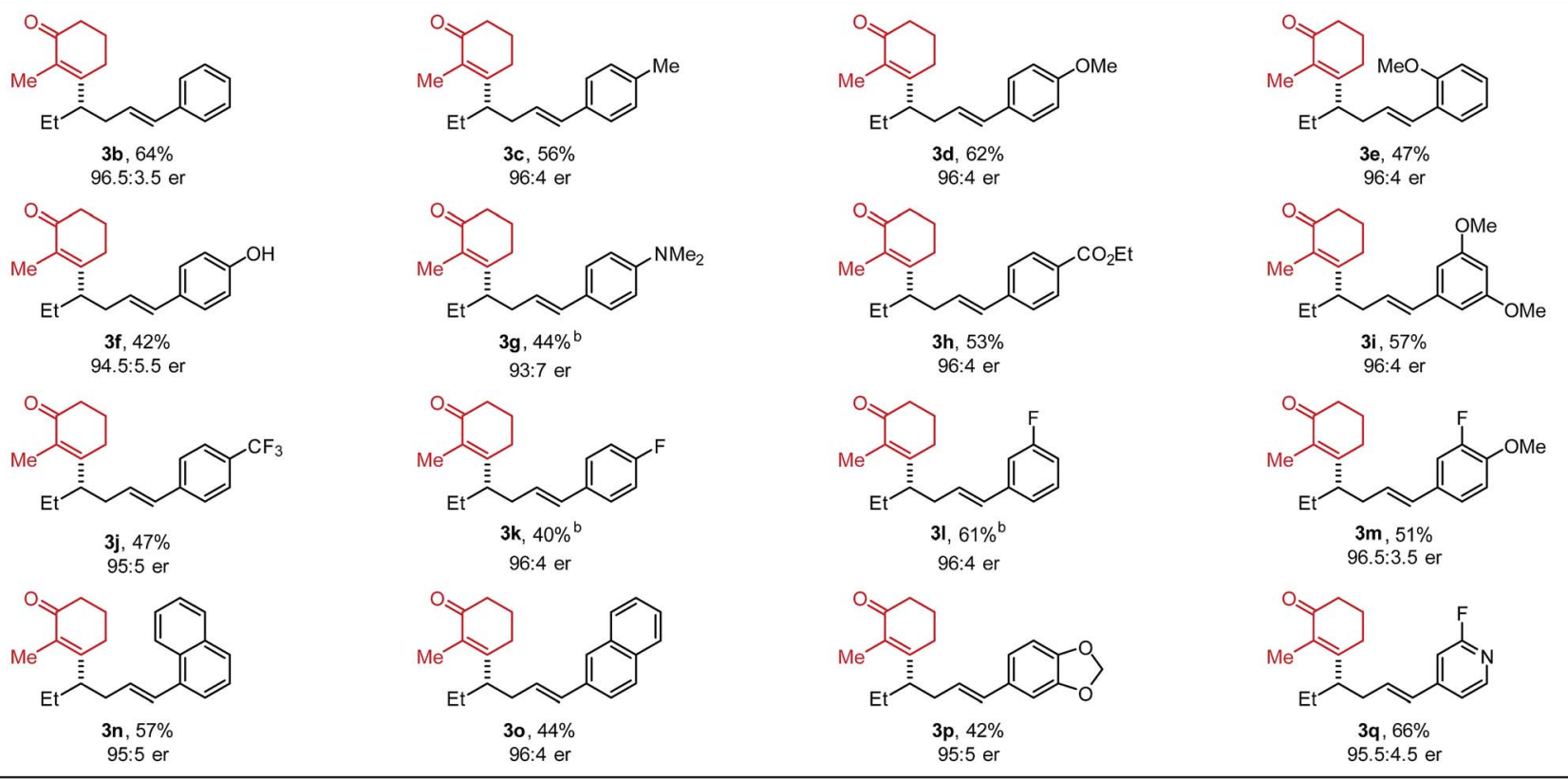

${ }^{a}$ Each entry represents the isolated yield on $0.2 \mathrm{mmol}$ scale. The er values were determined by SFC. ${ }^{b}$ No $p$-methoxyphenylbronoic acid was added.

migratory insertion products). On the basis of our previous work ${ }^{5 b}$ using $(Z)$-alkene substrates, the opposite enantiomer would be produced compared to reaction of the $(E)$-alkene. Thus, the absolute configuration of $\mathbf{3 z}$ and 3aa were assigned as $(R)$.

As alluded to above, interesting features of the reaction include the observation of alkene isomers using several of the differentiated aryl substrates as well as the inability to capture Pdalkyl intermediates through a subsequent cross-coupling. Therefore, we set out to interrogate the reaction mechanism with a focus on why the formation of the styrene product generally terminates the chain walking event(s). To initiate this investigation, deuterated alkenylbenzene $\mathbf{1} \mathbf{y}-\mathbf{D}_{\mathbf{2}}$ was subjected to the optimized reaction conditions with alkenyl triflate $\mathbf{2 a}$ (Table 5 ). The goal of this study was to determine the dynamics of the chain walking process. In the event, mono-deuterated products $3 \mathbf{y}(\mathbf{H}-\mathbf{D})$ and $3 \mathbf{y}(\mathbf{D}-\mathbf{H})$ were observed in $23 \%$ and $12 \%$ yield, respectively. In addition, di-deuterated product $3 \mathbf{3}(\mathbf{D}-\mathbf{D})$ was also observed in $12 \%$ yield. This mixture suggests the palladium catalyst undergoes reversible $\beta$-hydride elimination/migratory insertion at the benzylic position of the substrate, which results in the scrambling of the deuterium atoms.

To further probe the mechanism, we investigated the effect of various features of the terminating aryl group on the selective formation of styrenes. Specifically, a ratio of alkene products 3 and $\mathbf{4}$ was observed as a function of the aryl group (Fig. 1A). To probe this relationship, systematic changes of the terminal aryl on this ratio were evaluated while conserving the remainder of the reaction features (Fig. 1B), and the results were compared to a number of DFT-derived physical organic parameters. These were calculated using a simple aryl model system depicted in Fig. 1C. A correlation was identified between the observed product selectivity (represented as $\Delta \Delta G^{\ddagger}$ ) and the energy of an empty $\pi^{*}$ orbital as calculated by natural bond orbital (NBO) analysis (Fig. 1C). To validate this correlation, two extrapolations were tested that provide modestly improved selectivity. However, a substrate containing a para-Ph substituent performed in an unpredictable manner.

The discovery that relative $\pi^{*}$ orbital energy is correlative with the selectivity of alkene isomers formed, suggested that Pd may coordinate with the arene while chain walking. As the arene becomes less donating, the back-bonding interaction of the $\pi$ system with Pd, presumably favourable for the formation of the side product $\mathbf{4}$, is enhanced. ${ }^{11}$ To further inspect this hypothesis, computational optimization of intermediate structures was performed. The cationic organopalladium intermediate stabilized by interactions with both the alkenyl and the terminal aryl group is calculated to be $>10 \mathrm{kcal} \mathrm{mol}^{-1}$ lower in energy than the conformer leading up to $\beta$-hydride elimination, thus significantly raising the energy barrier of the chain walking process (Fig. 1D). Additionally, computational results support that, through the proposed palladium-Ar bonding interaction, the $\gamma$-palladium intermediates are stabilized in conformations prone to E2 elimination, with the a H-C-C-Pd dihedral angle of int-1a $\left(\varphi_{\text {int-1a }}\right)$ being $160.8^{\circ}$, and $\varphi_{\text {int-1b }}$ being $178.5^{\circ}$ (see ESI $\dagger$ for 
Table 3 Evaluation of alkenyl triflate scope ${ }^{a}$

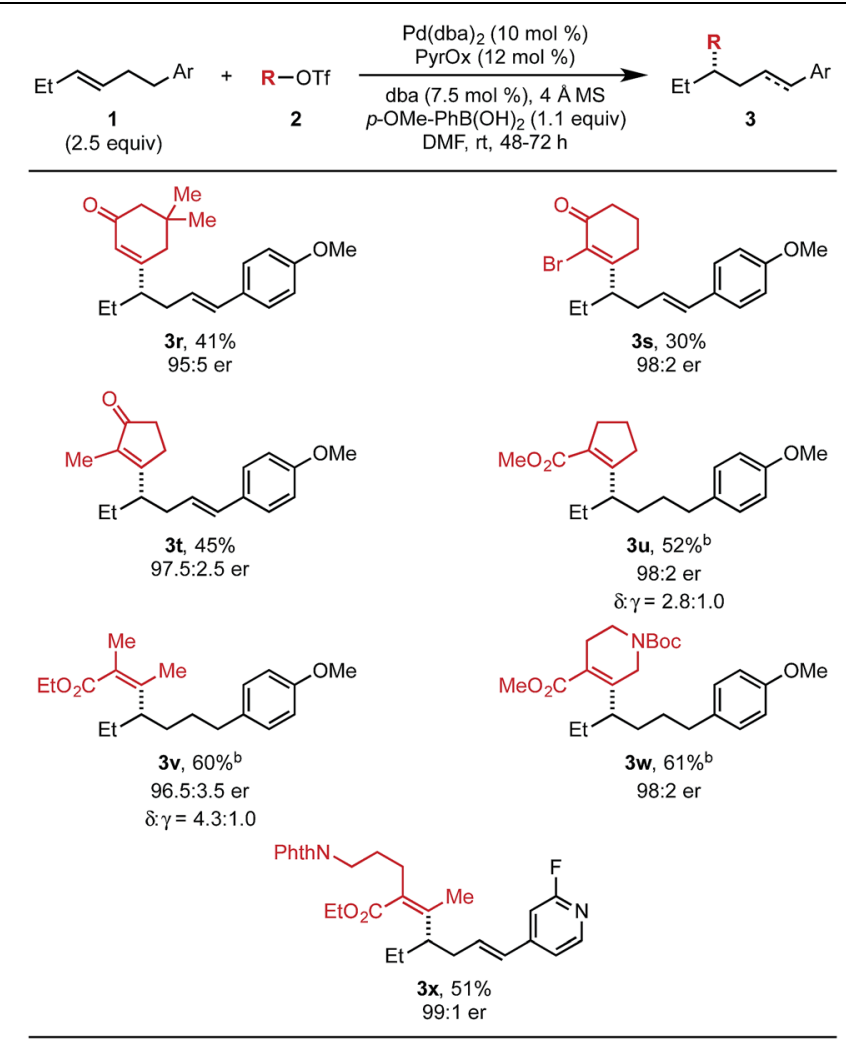

${ }^{a}$ Each entry represents the isolated yield on $0.2 \mathrm{mmol}$ scale. Er values were determined by SFC. ${ }^{b}$ The isolated yield was determined after hydrogenation using $\mathrm{Pd} / \mathrm{C}(2.5 \mathrm{~mol} \%), \mathrm{H}_{2}$ (balloon), in $\mathrm{MeOH}$.

Table 4 Evaluation of chain length ${ }^{a}$

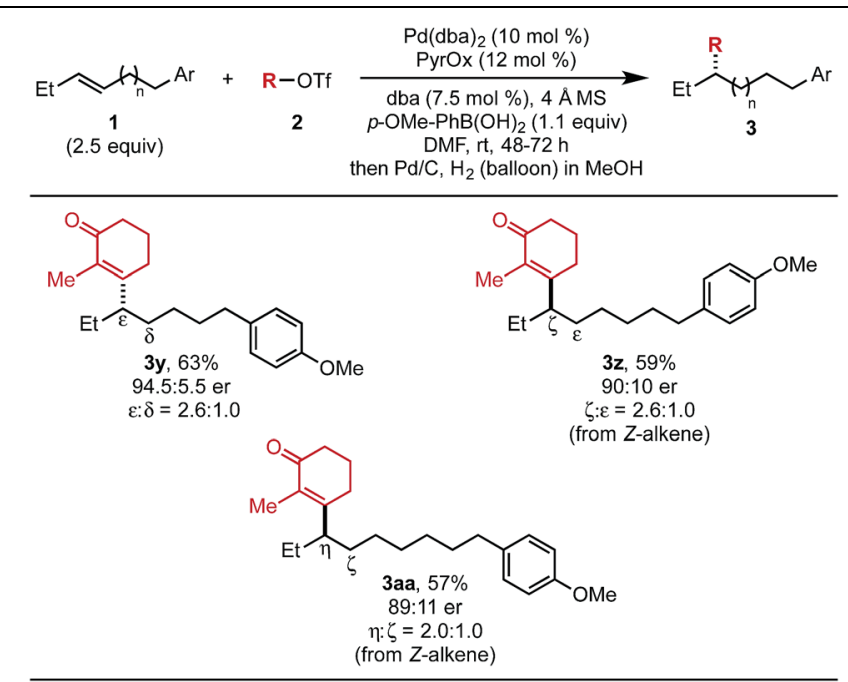

${ }^{a}$ Each entry represents the isolated yield on $0.2 \mathrm{mmol}$ scale. Er values were determined by SFC. ${ }^{b}$ The isolated yield was determined after hydrogenation using $\mathrm{Pd} / \mathrm{C}(2.5 \mathrm{~mol} \%), \mathrm{H}_{2}$ (balloon), in $\mathrm{MeOH}$.
Table 5 Deuterium labelling study ${ }^{a}$

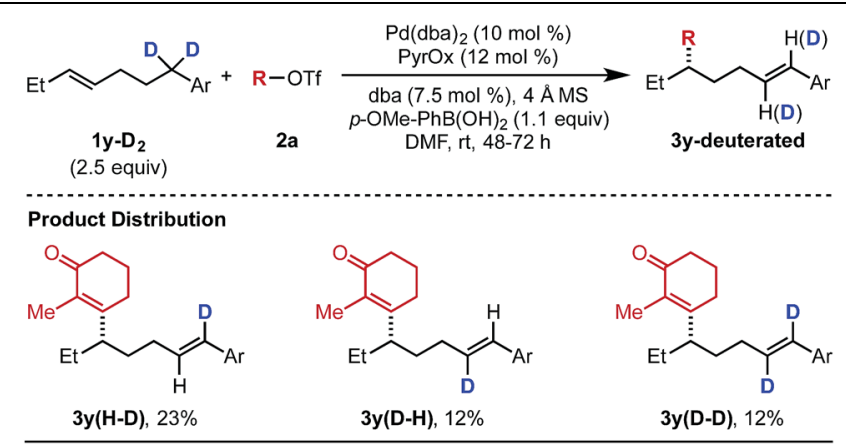

${ }^{a}$ Each entry represents the isolated yield on $0.2 \mathrm{mmol}$ scale.

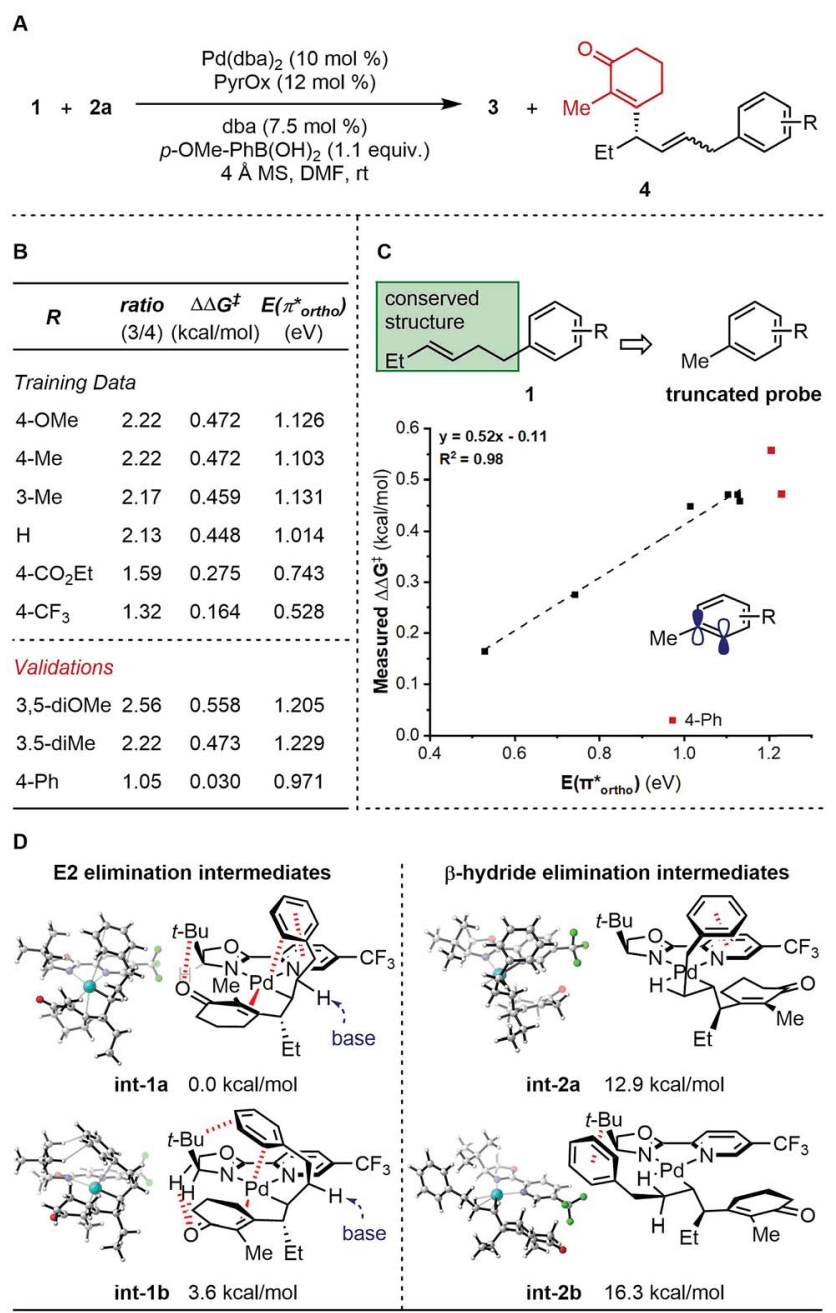

Fig. 1 Analysis of side product formation. (A) Reaction scheme. (B) Experimental data. (C) Quantitative analysis. (D) Proposed original of side products.

further details), which through solvent mediated deprotonation will lead to minor products 4 . A low-energy aryl $\pi^{*}$ orbital, which allows for strong back-bonding, can lead to both enhanced stabilizing effect, and an early transition state of the 
proposed E2 elimination process. The unexpected low selectivity observed for the para- $\mathrm{Ph}-\mathrm{C}_{6} \mathrm{H}_{4}$ substrate can be explained by the additional non-covalent interactions of the para-position phenyl group with the ligand backbone, which further stabilizes the organopalladium intermediate for elimination. ${ }^{12,5 d}$

\section{Conclusions}

In summary, we have successfully developed an intermolecular enantioselective alkenylative relay Heck reaction of alkenylbenzene derivatives to synthesize enantiomerically enriched $\beta$-substituted styrenes in good to high enantioselectivity. Preliminary mechanistic studies suggest reversible $\beta$-hydride elimination/migratory insertion to arrive at the thermodynamic styrenyl product. This information will provide the foundation for the future development of new termination strategies using a metal-chain walking reaction process.

\section{Conflicts of interest}

There are no conflicts to declare.

\section{Acknowledgements}

The work was supported by National Institute of Health (NIGMS R01GM063540). The support and resources from the Center for High Performance Computing at the University of Utah are gratefully acknowledged.

\section{References}

1 For selected reviews, see: (a) R. Uma, C. Crévisy and R. Grée, Chem. Rev., 2003, 103, 27; (b) N. Kuznik and S. Krompiec, Coord. Chem. Rev., 2007, 251, 222; (c) S. Krompiec, M. Krompiec, R. Penczek and H. Ignasiak, Coord. Chem. Rev., 2008, 252, 1819; (d) E. Larionov, H. Li and C. Mazet, Chem. Commun., 2014, 50, 9816; (e) M. Hassam, A. Taher, G. E. Arnott, I. R. Green and W. A. L. van Otterlo, Chem. Rev., 2015, 115, 5462; $(f)$ M. Vilches-Herrera, L. Domke and A. Börner, ACS Catal., 2014, 4, 1706; $(g)$ A. Vasseur, J. Bruffaerts and I. Marek, Nat. Chem., 2016, 8, 209; (h) H. Sommer, F. JuliáHernández, R. Martin and I. Marek, ACS Cent. Sci., 2018, 4, 153.

2 Selected examples and reviews on olefin polymerization, see:

(a) M.-H. Prosenc and H.-H. Brintzinger, Organometallics, 1997, 16, 3889; (b) Z. Guan, P. M. Cotts, E. F. McCord and S. J. McLain, Science, 1999, 283, 2059; (c) S. D. Ittel, L. K. Johnson and M. Brookhart, Chem. Rev., 2000, 100, 1169.

3 E. W. Werner, T.-S. Mei, A. J. Burckle and M. S. Sigman, Science, 2012, 338, 1455.

4 Selected examples: for Rh-catalyzed chain walking, see $(a)$ K. Yoshida and T. Hayashi, J. Am. Chem. Soc., 2003, 125, 2872; (b) A. J. Borah and Z. Shi, J. Am. Chem. Soc., 2018, 140, 6062; for Pd-catalyzed chain walking, see (c) C. C. Oliveira, R. A. Angnes and C. R. D. Correia, J. Org. Chem., 2013, 78, 4373; (d) E. Larionov, L. Lin, L. Guénée and C. Mazet, J. Am. Chem. Soc., 2014, 136, 16882; (e) T. Hamasaki, Y. Aoyama, J. Kawasaki, F. Kakiuchi and
T. Kochi, J. Am. Chem. Soc., 2015, 137, 16163; (f) S. Singh, J. Bruffaerts, A. Vasseur and I. Marek, Nat. Commun., 2017, 8, 14200; $(g)$ D. G. Kohler, S. N. Gockel, J. L. Kennemur, P. J. Waller and K. L. Hull, Nat. Chem., 2018, 10, 333; for Co-catalyzed chain walking, see $(h) \mathrm{J}$. V. Obligacion and P. J. Chirik, J. Am. Chem. Soc., 2013, 135, 19107; for Nicatalyzed chain walking, see $(i)$ W.-C. Lee, C.-H. Wang, Y.-H. Lin, W.-C. Shih and T.-G. Ong, Org. Lett., 2013, 15, 5358; (j) Y. He, Y. Cai and S. Zhu, J. Am. Chem. Soc., 2017, 139, 1061; (k) F. Juliá-Hernández, T. Moragas, J. Cornella and R. Martin, Nature, 2017, 545, 84; (l) L. Peng, Y. Li, Y. Li, W. Wang, H. Pang and G. Yin, ACS Catal., 2018, 8, 310; $(\mathrm{m})$ Z. Wang, H. Yin and G. C. Fu, Nature, 2018, 563, 379. 5 Selected examples: (a) T.-S. Mei, E. W. Werner, A. J. Burckle and M. S. Sigman, J. Am. Chem. Soc., 2013, 135, 6830; (b) T.-S. Mei, H. H. Patel and M. S. Sigman, Nature, 2014, 508, 340; (c) C. Zhang, C. B. Santiago, J. M. Crawford and M. S. Sigman, J. Am. Chem. Soc., 2015, 137, 15668; (d) Z.-M. Chen, M. J. Hilton and M. S. Sigman, J. Am. Chem. Soc., 2016, 138, 11461; (e) N. J. Race, C. S. Schwalm, T. Nakamuro and M. S. Sigman, J. Am. Chem. Soc., 2016, 138, 15881; $(f)$ Z.-M. Chen, C. S. Nervig, R. J. Deluca and M. S. Sigman, Angew. Chem., Int. Ed., 2017, 56, 6651; $(g)$ Q. Yuan and M. S. Sigman, J. Am. Chem. Soc., 2018, 140, 6527.

6 (a) L. Xu, M. J. Hilton, X. Zhang, P.-O. Norrby, Y.-D. Wu, M. S. Sigman and O. Wiest, J. Am. Chem. Soc., 2014, 136, 1960; (b) M. J. Hilton, L.-P. Xu, P.-O. Norrby, Y.-D. Wu, O. Wiest and M. S. Sigman, J. Org. Chem., 2014, 79, 11841.

7 C. Zhang, C. B. Santiago, L. Kou and M. S. Sigman, J. Am. Chem. Soc., 2015, 137, 7290.

8 (a) H. H. Patel and M. S. Sigman, J. Am. Chem. Soc., 2015, 137, 3462; (b) H. H. Patel and M. S. Sigman, J. Am. Chem. Soc., 2016, 138, 14226.

9 H. M. Nelson, B. D. Williams, J. Miró and F. D. Toste, J. Am. Chem. Soc., 2015, 137, 3213.

10 For details on the assignment of absolute configuration, please see the ESI. $\dagger$

11 (a) A. Falceto, E. Carmona and S. Alvare, Organometallics, 2014, 33, 6660; (b) S. M. Reid, R. C. Boyle, J. T. Mague and M. J. Fink, J. Am. Chem. Soc., 2003, 125, 7816; (c) B. W. Smucker, J. M. Hudson, M. A. Omary and K. R. Dunbar, Inorg. Chem., 2003, 42, 4714; (d) B. Inés, R. SanMartin, F. Churruca, E. Domínguez, M. K. Urtiaga and M. I. Arriortua, Organometallics, 2008, 27, 2833; (e) K. Wieghardt, H. J. Küppers, E. Raabe and C. Krüger, Angew. Chem., Int. Ed. Engl., 1986, 25, 1101.

12 Selected examples on non-covalent interactions application in selective catalysis, see: (a) C. D. Sherrill, Acc. Chem. Res., 2013, 46, 1020; (b) F. D. Toste, M. S. Sigman and S. J. Miller, Acc. Chem. Res., 2017, 50, 609; (c) A. J. Neel, M. J. Hilton, M. S. Sigman and F. D. Toste, Nature, 2017, 543, 637; (d) M. Orlandi, J. A. S. Coelho, M. J. Hilton, F. D. Toste and M. S. Sigman, J. Am. Chem. Soc., 2017, 139, 6803; (e) R. A. Angnes, L. M. Thompson, M. S. Mashuta, C. R. D. Correia and G. B. Hammond, Adv. Synth. Catal., 2018, 360, 3760 . 